\title{
A 72-YEAR-OLD LADY WITH URINARY INCONTINENCE: A CASE STUdy
}

\begin{abstract}
Urinary incontinence is a far-reaching and complex problem for older persons and has major psychosocial, economic and health consequences in affected women. The aim of this case report is to demonstrate that simple physiotherapeutic intervention can bring about dramatic improvement in the continence status of a patient and as a result improve the quality of life of such a patient. A literary review, the patient history, profile and the findings of the physical examination are presented. Physiotherapy and the outcomes are futher discussed.
\end{abstract}

\section{VAN DER SPUY A, Dip Physio (UOF); HED (UP) ${ }^{1}$ PAPADOPOULOS $M$, MSc Physio (WITS)}

'Deparment of Physiotherapy, University of Pretoria 2 Department of Physiotherapy, University of Pretoria

\section{KEYWORDS: PHYSICAL THERAPY, URINARY INCONTINENCE, CONSERVATIVE MANAGEMENT}

$\mathrm{U}$ rinary incontinence is a farreaching and complex complaint amongst older persons and has major psychosocial, economic and health consequences in affected women (Hertzog \& Fultz, 1990). The physiotherapist can play a vital part in alleviating the symptoms of incontinence and thereby improving the quality of life in patients suffering from urinary incontinence. The aim of this case report is to demonstrate that simple physiotherapeutic intervention can bring about dramatic improvement in the continence status of a patient and as a result improve the quality of life of such a patient.

\section{PATIENT PROFILE AND HISTORY}

The patient (a 72-year-old lady) was referred for physiotherapy, by the department of urology, University of Pretoria, with a diagnosis of severe stress incontinence. She had had numerous consultations with different urologists but had never been referred for physiotherapy. As she couldn't find a physiotherapist in her vicinity agreeable to treat her, she contacted, on her own initiative, the physiotherapy department at the University of Pretoria.

The patient had been suffering from stress incontinence for the past eleven years.

She has two children who were born by means of vaginal delivery and with instrumentation. After the second birth she remembers suffering from mild incontinence. Her incontinence started after she had a vaginal hysterectomy eleven years ago. Since then she has undergone seven surgical procedures for her incontinence but to no avail. For the past four years, it has rendered her housebound and unable to socialise, shop or attend church services. She described her quality of life as poor. She complained of recurrent urinary tract infections, which complicated her situation even further. Apart from her incontinence, she has no other relevant medical problems and uses no medication which could influence her condition.

\section{PHYSICAL EXAMINATION}

On examination, the skin in the groin and around the external genitalia was found to be red and she had a perianal rash. Pelvic floor strength graded $I$ out of 3 on the Circumvaginal muscle scale as she was totally unable to contract her paravaginal muscles (Worth et al, 1986).

\section{PHYSIOTHERAPY}

The physiotherapy session started with patient education embracing all the relevant concepts of incontinence. Information was given to the patient, as well as to her husband who accompanied her.

Initial treatment consisted of interferential therapy, using an intra-vaginal electrode. A base frequency of $2000 \mathrm{~Hz}$ was used as it has the best effect on the striated muscle found in the external sphincter of the bladder. Amplitude modulation frequency (AMF) of $50 \mathrm{~Hz}$ was used, which has the best circulatory effect (Hogenkamp et al, 1987). A ratio of a 10 to 20 second contraction period and a 50-second rest period was used in order to allow adequate recuperation of the small damaged muscles of the perineum. The treatment time was $30 \mathrm{mi}-$ nutes and was divided into 2 sessions of 15 minutes each with a 5-minute rest period in-between. The interferential current intensity was maximum, just below the patient's pain threshold and not causing any discomfort. The patient was encouraged to contract her perineal muscles maximally while the current was surging. During the course of the treatment, progression was aimed at producing a maximal perineal muscle contraction with a progressively lower current intensity. The patient was treated

CORRESPONDENCE

Ms A van der Spuy Department of Physiotherapy

University of Pretoria PO Box 667

Pretoria 0001

Tel: (012) 354-2023 
3 times a week for a total number of 12 treatments.

By the second week of treatment $\left(4^{\text {th }}\right.$ treatment), in addition to the interferential therapy, the patient was instructed to do perineal floor muscle exercises (PFME). She was instructed to practice 3 times every day (see Table 1 for further details). She was further told to empty her bladder only every two hours and to consciously make use of the perineal muscle floor control which she had attained. The patient reported at each subsequent physiotherapy session that she had diligently followed these instructions.

During the third week of treatment ( $8^{\text {th }}$ treatment), vaginal cones, as an addition to her pelvic floor muscle exercises, were added to her exercise programme. On her return for the $9^{\text {th }}$ treatment, the patient reported that she had struggled to insert a vaginal cone and therefor could not manage to perform this part of her home-exercise regime. Subsequently the physiotherapist helped her to insert a vaginal cone and to contract her pelvic floor muscles. The patient was instructed to re-attempt this exercise at home. At her $10^{\text {th }}$ visit to the physiotherapist, the patient again complained that she had difficulty inserting a vaginal cone. She described it as "awkward" and an "unnatural" exercise for an "old lady". Any further attempts at using the vaginal cones as part of her exercise programme were therefor discontinued. The patient was told to maintain the perineal muscle strength by constantly contracting her muscles and by consciously using them in bladder control.

\section{OUTCOME}

Table I presents the improvement, both subjectively and objectively,during the 12 -session treatment period. The patient reported after the $3^{\text {rd }}$ treatment that she already had better control. She admitted that she previously hadn't been aware of the fact that a contraction of the perineal muscles is possible. By the $8^{\text {th }}$ treatment she reported that she had improved dramatically and that she had been shopping the previous day. By the $11^{\text {th }}$ treatment the patient reported continence for the whole day except towards the late afternoon, when she became tired and had an occasional lapse. The condition of the skin in the groin and genitalia also demonstrated a dramatic improvement by the $12^{\text {th }}$ treatment.

Six months after completion of the treatment course, the patient was contacted telephonically. She was delighted to report that the recurrent urinary tract infections had disappeared and she was fully continent and that she was once more leading an active and productive life! One year later, she was still continent!

\section{DISCUSSION}

Urinary incontinence is a common problem in the elderly and it is associated with staggering social and economic costs. Sufferers give up many aspects of their lives with obvious detriment to their social interactions, inter-personal and sexual relationships, careers and psychosocial wellbeing (Kelleher et al, 1997). Affected women initially change their exercise habits and eventually, after particularly frequent incontinent episodes, their social habits. Such was the case in this patient. This patient was desperate to be cured of her incontinence. The seven surgical procedures and the great monthly expense for sanitary wear, apart from the discomfort, placed a large financial burden on her and her husband's lives as pensioners.

Conservative management of incontinence has been shown to be effective both in improving incontinence and improving patient well being (Wyman $e t$ al, 1992; O'Brien et al, 1991). Surgical treatment for patients with stress incontinence is indicated in the presence of severe symptoms which have failed to

\section{TABLE 1: SUBJECTIVE AND OBJECTIVE IMPROVEMENT IN PELVIC FLOOR MUSCLE STRENGTH AS EVALUATED DURING}

THE 12 PHYSIOTHERAPY SESSIONS.

\begin{tabular}{|c|l|c|l|}
\hline SESSION & \multicolumn{1}{|c|}{ PHYSIOTHERAPY } & $\begin{array}{c}\text { PELVIC } \\
\text { FLOOR } \\
\text { MUSCLE } \\
\text { STRENGTH }\end{array}$ & \multicolumn{1}{c|}{$\begin{array}{c}\text { PATIENT } \\
\text { COMMENT }\end{array}$} \\
\hline $182 \& 3$ & Patient education, Interferential therapy. & $1 / 3$ & No control over bladder function. \\
\hline $4 \& 5 \& 6$ & $\begin{array}{l}\text { As above. } \\
\text { Add PFME in supine (4 sets of 10). }\end{array}$ & $2 / 3$ & $\begin{array}{l}\text { "Slightly" more control over bladder } \\
\text { function. }\end{array}$ \\
\hline $7 \& 8 \& 9$ & $\begin{array}{l}\text { As above. } \\
\text { Add PFME in side-lying and standing } \\
\text { (4 sets of 20). } \\
\text { Add vaginal cones during session 8. } \\
\text { Discontinue vaginal cones from exercise } \\
\text { program at session 10. }\end{array}$ & $\begin{array}{l}\text { "Definite" better control over bladder } \\
\text { function. } \\
\text { Vaginal cones are "awkward". } \\
\text { Went for shopping the day before session-8 } \\
\text {-the first time in 4 years. }\end{array}$ \\
\hline $10 \& 11 \& 12$ & $\begin{array}{l}\text { As above. } \\
\text { Add PFME with coughing, } \\
\text { climbing stairs and lifting } \\
\text { (4 sets of 30). }\end{array}$ & $3 / 3$ & $\begin{array}{l}\text { Fully continent the whole day except } \\
\text { towards the evening. }\end{array}$ \\
\hline
\end{tabular}


respond to conservative measures (Hilton, 1987). It is sad that none of the urologists consulted by this lady, ever mentioned the possibility of physiotherapy which could improve her condition. It is speculated that the reasons for this might be: either that the urologists were not aware of the beneficial effects of physiotherapy for incontinence, or that they might not have thought that conservative measures could cure this patient. Another factor that should be taken into account was the unavailability of a physiotherapist willing to treat her, even after a urologist had successfully diagnosed her. Physiotherapists need to ask themselves "how could this be possible" especially in the light of the fact that the role of physiotherapy in the management of incontinence has been well described. It is surprising that physiotherapists consulted, did not refer her to these specialist-physiotherapists who deal with incontinence. The efficacy of conservative intervention, even in a patient who has undergone several surgical procedures, cannot and should not be ignored. It is not appropriate however, to extrapolate these findings to other patients in the same situation, as each situation is different and should be assessed under well-controlled circumstances.

According to Berghams et al (1996) pelvic floor muscle training with biofeedback and/or pelvic floor muscle training alone are effective treatment modalities for patients suffering from mild or moderate stress incontinence. In patients with dysfunction of the pelvic floor without awareness of the pelvic floor muscles (i.e. the patient has no ability to contract or relax the pelvic floor muscles), digital assessment by means of transvaginal palpation, performed by the patient or by the physiotherapist, electrostimulation and/or biofeedback is indicated. Successful restoration of awareness of these muscles, must be achieved before pelvic floor muscle exercises are possible. Firstly, isolated contractions of the pelvic floor must be carried out and then incorporating them into activities of daily living, initially during simple tasks and progressing to more complex tasks, in order to achieve a well orchestrated, automatic control of the pelvic floor. The management of this patient was based on this rationale.

Electrostimulation (interferential therapy) without biofeedback was used in this patient. De Kruif \& Van Wegen (1996) mentioned that electrostimulation focuses on the restoration of reflex activity by excitation of the pudendal nerves, in order to create a pelvic floor muscle contraction. If the pudendal nerve is intact, electrostimulation will induce a motor-response in patients where voluntary contraction of the pelvic floor muscles is a problem, and subsequently re-education of insufficient pelvic floor muscles can be commenced. According to this concept, adequate electrostimulation provides reflex contraction of striated para-and periuretheral muscles, based on afferent excitation of the pelvic floor. If awareness cannot be achieved, the patient has to be sent back for further evaluation by a specialist. An insufficient restoration of awareness can be the consequence of undiagnosed neurologic disorders, sometimes concurrent with endopelvic fascia lesions eg after a traumatic delivery. Electrostimulation will also support the transformation from fatigable fibres to fatigue-resistant fibres (Pette \& Vrbova, 1985). Apart from the increase in muscle strength, the improvement in this patient may be attributed to the fact that electrostimulation and exercise resulted in the pelvic muscle fibres becoming fatigue resistant. This was evident from the patient's report after the $11^{\text {th }}$ treatment namely that "she was continent for the whole day except towards the evening when she became tired".

The fact that the patient couldn't manage to use the vaginal cones, and described it as "awkward" etc is very interesting. No other documented evidence of this nature has been reported previously to the best knowledge of the authors. Compassionate management of the patient's predicaments and obvious preferences are extremely important factors in developing trust and compliance. Incontinence is often cited as being a highly distressing and disabling condition causing a great deal of anxiety and depression (Resnick, 1996). Additional embarrassment should therefor be prevented at all costs.

\section{CONCLUSION}

Urinary incontinence has a significant effect on an individual 's quality of life. Conservative measures used include education, electrical stimulation and pelvic floor muscle exercises. Physiotherapy has been shown to be effective in the management of stress incontinence and can therefor result in a marked improvement in the quality of life of an incontinence sufferer.

To achieve these results, constant supervision, support and encouragement must be provided by the physiotherapist.

\section{REFERENCES}

Berghams LCM, Frederiks CMA, De Bie RA, Van Waalwijk van Doorn ESC, Janknegt RA (1996): Efficacy of biofeedback when included with pelvic floor muscle exercise treatment for genuine stress incontinence. Neurourology and Urodynamics 15:37-52.

De Kruif YP, Van Wegen EEH (1996): Pelvic floor muscle exercise therapy with myofeedback for woman with stress urinary incontinence: a meta-analysis. Physiotherapy $82(2)$ : 107-113.

Hertzog AR, Fultz NH (1990). Prevalence and incidence of urinary incontinence in community-dwelling populations. Journal of the American Geriatrics Society 38:273-281.

Hilton P (1987): Urinary incontinence in woman. British Medical Journal 295:426-432.

Hogenkamp M, Mittelmeijer E, Smits I, Van Stralen C (1987): Interferential therapy. EnrafNonius Delft, 3 rd revised edition.

Kelleher CJ, Cardazo LD, Khullar V, Salvatore $S$ (1997): A new questionnaire to assess the quality of life of urinary incontinent women. British Journal of Obstetrics an Gyneacology 104: 1374-1379.

O'Brien J, Austin M, Sethi P, O'Boyle P (1991). Urinary incontinence: prevalence, need for treatment and effectiveness of intervention by nurse. British Medical Journal 303: 1308-1312.

Pette D, Vrbova G (1985): Invited review: Neural control of phenotypic expression in mammalian muscle fibres. Muscle Nerve 8 : 676-689.

Resnick NM (1996): An 89 year old woman with urinary incontinence. Journal of the American Medical Association 276(22): 1832-1840.

Worth AM, Dougherty MC, McKey PL (1986): Development and testing of the Circumvaginal Muscle Rating Scale: Nursing Research 35(3): 166-168.

Wyman JF, McClish DK, Ory MF, Fant JA (1992): Changes in quality of life following bladder training in older women with urinary incontinence. Neurourology and urodynamics 11: $425-427$ 